\title{
Recognition of the Y chromosome in Turner syn- drome using peripheral blood or oral mucosa tissue
}

\author{
Lene Garcia Barbosa', \\ Adriana Aparecida Siviero- \\ Miachon', \\ Maria Anunciação Souza², \\ Angela Maria Spinola-Castro' \\ ${ }^{1}$ Division of Pediatric Endocrinology, \\ Department of Pediatrics in Federal \\ University of Sao Paulo (UNIFESP- \\ EPM), Sao Paulo, Brazil \\ ${ }^{2}$ Neuroscience and Cognition \\ in Federal University ABC, Santo \\ André, Brazil
}

Purpose: Turner syndrome is defined as total or partial loss of the second sex chromosome in a phenotypically female patient. Due to the possibility of hidden mosaicism of fragments of the $Y$ chromosome and development of gonadoblastoma, we evaluated the presence of such fragments in 2 tissues with different embryonic origins, peripheral blood lymphocytes (mesoderm), and oral mucosal cells (ectoderm) using multiplex polymerase chain reaction.

Methods: DNA samples were collected from 109 patients, and primers for the SRY, TSPY, and AMELX genes were used.

Results: We found 14 patients (12.8\%) with positive molecular markers for the $Y$ chromosome. The study of tissues of different embryological origin showed the same degree of agreement, sensitivity, and specificity.

Conclusion: Oral mucosa cells have a simpler method of collection that is less invasive and requires less time for DNA extraction at a lower cost.

Keywords: Turner syndrome, Polymerase chain reaction, $\mathrm{Y}$ chromosome, Oral mucosa, Peripheral blood

\section{Highlights}

- Detection of the Y chromosome is important due to the risk of tumor development in Turner syndrome (TS) .

- Karyotype is the gold standard for diagnosing TS, but it has low sensitivity to identify Y chromosome mosaicism.

- Detection of the $\mathrm{Y}$ chromosome in different tissues is a predictor of its presence in the gonads.

\section{Introduction}

Turner syndrome (TS) occurs in about 1 in every 2,500 female newborns and is one of the most common chromosomal disorders. It is characterized by short stature, ovarian failure, and other somatic abnormalities such as congenital lymphedema, winged neck, eyelid ptosis, and low posterior hairline implantation. ${ }^{1)}$ The changes are related to complete or partial loss of one of the X chromosomes (40\% to $60 \%$ ) or presence of part of the Y chromosome (5\%). ${ }^{2)}$ It has been proposed that hidden $Y$ fragment mosaicism occurs more frequently than described and depends on methodological approach. ${ }^{3}$ From a clinical point of view, detection of the Y chromosome is particularly important due to the risk of gonadoblastoma in $27 \%-30 \%$ of women with TS. ${ }^{4)}$

Cytogenetic analysis of 30 metaphases is able to detect a percentage of mosaicism greater than $10 \%$ (95\% trustworthy). To detect mosaicism at lower than $10 \%$, it is necessary to analyze a much larger number of cells, which is expensive and time-consuming. ${ }^{5)}$ To be viable, a $45, \mathrm{X}$ conceptus must contain, at some critical period during embryogenesis, another cell

\footnotetext{
Address for correspondence: Lene Garcia Barbosa

Division of Pediatric Endocrinology, Department of Pediatrics in Federal University of Sao Paulo (UNIFESPEPM), Sao Paulo, Brazil,340 José de Magalhães Street, São Paulo 04026090, Brazil

Email: lenegb69@gmail.com https://orcid.org/0000-0003-23609305
} 
line. Due to that, many women with karyotypes presenting $\mathrm{X}$-chromosome monosomy are mosaics, although this might not be detected in peripheral blood but in other tissues. ${ }^{6}$

With the introduction of molecular techniques such as polymerase chain reaction (PCR), there has been an increase in the detection of hidden $\mathrm{Y}$ chromosome mosaicism, which was not detected in cytogenetic examinations. ${ }^{7-9)}$ The multiplex PCR (mPCR) technique is a useful and reliable tool for specific detection of small amounts of DNA in a single reaction, surpassing conventional PCR, which detects a single sequence per reaction. Due to the simplicity, speed, and cost efficiency, this technique has been used in several studies. ${ }^{10-13)}$

The aim of this work was to use the MPCR technique to investigate the presence of hidden $\mathrm{Y}$ chromosome mosaicism in patients with TS who have X monosomy or ring chromosomes and to compare 2 tissues with different embryonic origins, peripheral blood lymphocytes (mesoderm), and oral mucosa cells (ectoderm).

\section{Materials and methods}

\section{Study population}

In total, 109 patients diagnosed with TS were followed at the Pediatric Endocrinology and Clinical Endocrinology Clinic of the Federal University of São Paulo. The distribution of karyotypes is shown in Table 1. The study was approved by the Medical Ethics and Research Committee (CAE: 48099115.0.0000.5505), and all participants signed an informed consent form.

\section{Methods}

\section{1) Clinical assessment}

The following clinical data were obtained from medical records: age at diagnosis of TS, age at sample collection for DNA extraction, number of metaphyses analyzed, and age at gonadectomy.

The mean age of the patients at diagnosis was 9.3 years (minimum of 1 month and maximum of 54 years, with standard deviation of 8.5 years), and the average age at sample collection for DNA extraction was 22 years (minimum of 1 year and maximum of 60 years, with a standard deviation of 11.7 years). Karyotyping was performed with an average analysis of 30

Table 1. Karyotypes of patients with Turner syndrome selected for the study

\begin{tabular}{lc}
\hline Karyotype & Frequency $(\mathrm{n})$ \\
\hline $45, \mathrm{X}$ & 101 \\
$46, \mathrm{X}, \mathrm{r}(?)$ & 1 \\
$45, \mathrm{X} / 46, \mathrm{X}, \mathrm{r}(?)$ & 5 \\
$45, \mathrm{X} / 47, \mathrm{X},+$ mar1,+mar2 & 1 \\
$45, \mathrm{X} / 47, \mathrm{X},+$ mar1, +mar2/48,X,+mar1,+mar2,+mar3 & 1 \\
Total & 109 \\
\hline
\end{tabular}

metaphases (ranging from 15 to 53).

2) Evaluation of $Y$ chromosome

Blood samples $(3 \mathrm{~mL})$ from the patients were collected in tubes with ethylene diamine tetraacetic acid and kept at $4{ }^{\circ} \mathrm{C}$ until processing. Genomic DNA was obtained using the modified Bowtell method. ${ }^{14)}$ Commercial kits were used following the manufacturer's recommendations (Gentra Puregene Blood Kit, QIAGEN, Venlo, Netherlands).

Samples of oral mucosa cells were collected using 2 sterile cytological brushes. The collection was performed after oral rinsing with filtered water following the manufacturer's recommendations (commercial DNA isolation kit, QIAGEN) and scraping the inside of the cheeks with the brush (one for each side) using approximately 10 circular movements. The brushes were placed separately in 15-mL Falcon tubes, and 300 $\mu \mathrm{L}$ of cell lysis solution was added. The collected samples were stored at room temperature $\left(15^{\circ} \mathrm{C}\right.$ to $\left.25^{\circ} \mathrm{C}\right)$ until extraction. The DNA of leukocytes from peripheral blood and from oral mucosa cells was stored in a freezer $\left(-20^{\circ} \mathrm{C}\right)$ until mPCR amplification, which varied from days to months.

The primers used for the SRY, TSPY, and AMELX genes and the PCR conditions were described by Barbosa et al. ${ }^{13}$. Classical markers, such as DYZ3 and DYZ1, have been mentioned as isolated cases have shown similar or inferior results compared to the SRY and TSPY markers. ${ }^{15-18)}$

\section{Statistical analysis}

For statistical analysis, the IBM SPSS Statistics ver. 20.0 (IBM Co., Armonk, NY, USA), Minitab 16, and Excel Office 2013 were used. Parametric statistical tests were used based on the normality of the quantitative variables of the main outcome, as tested using the Kolmogorov-Smirnov test. The chi-square test was used to verify whether 2 variables and their response levels demonstrated statistical dependence (association) or not and to assess the sensitivity and specificity of the diagnostic test.

Fleiss' kappa agreement analysis was performed to describe the agreement between 2 tissues from the same patient. The value of kappa coefficient can vary between 0 and 1 . The closer is the value to 1 , the greater is the indication of agreement between the tissues; the closer is the value to zero, the greater is the indication of randomness (kappa $<0.200$ as negligible; 0.210 to 0.400 as minimal; 0.410 to 0.600 as regular; 0.610 to 0.800 as good; above 0.810 as optimal). The $95 \%$ confidence interval (CI) was adopted, and the P-value of statistical significance was $<0.05$.

\section{Results}

Among the 109 patients with TS, 14 (12.8\%) had positive molecular markers (TSPY and SRY) in both the blood and the oral mucosa (Fig. 1, Table 2). Gonadectomy had been performed in 7 patients, and a pattern of diagenetic gonads was found: 


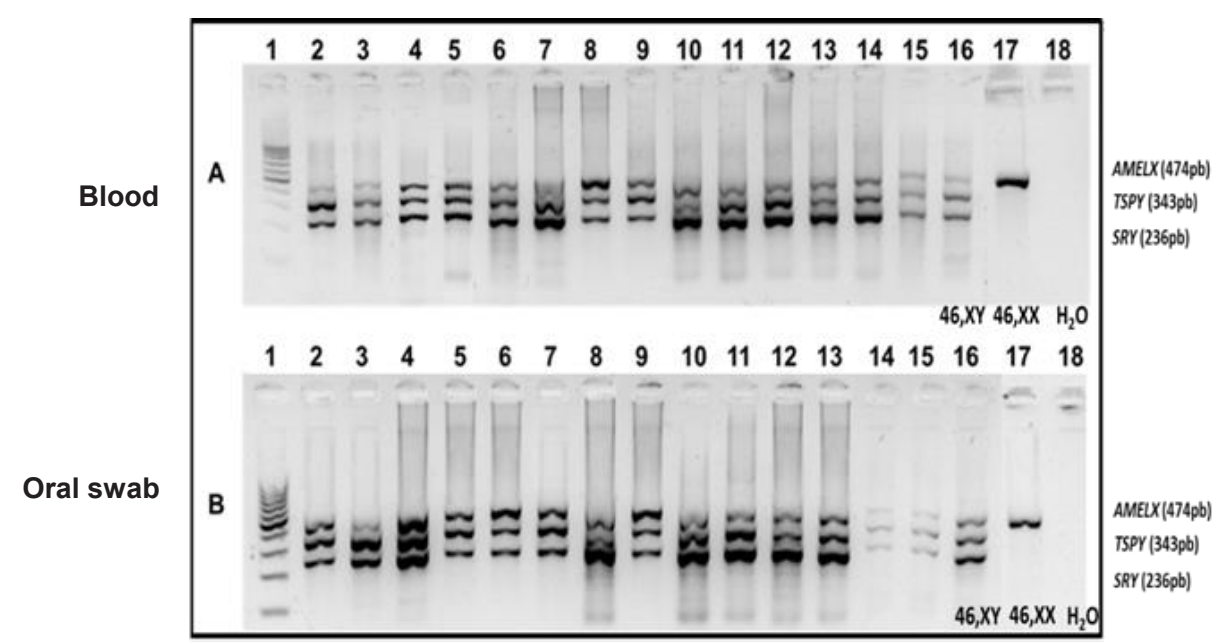

Fig. 1. Agarose gel electrophoresis at $1.8 \%$ of the multiplex polymerase chain reaction (MPCR) of Y-positive samples. (A) Multiplex PCR samples in peripheral blood leukocytes. (B) Oral mucosa swab samples. Channel 1: 100-pb ladder, channels 2 to 15: patients, channel 16: control 46, XY, channel 17: control 46, XX, and channel 18: white control. Genes: $S R Y=236 \mathrm{bp} ; T S P Y=343 \mathrm{bp}$, and $A M E L X=474 \mathrm{bp}$.

Table 2. Characteristics of patients with positive molecular studies for $Y$ markers

\begin{tabular}{lccc}
\hline Karyotype & $\begin{array}{c}\text { No. of metastases analyzed for } \\
\text { the karyotype }\end{array}$ & $\begin{array}{c}\text { Age at diagnosis of } \\
\text { Turner syndrome (yr) }\end{array}$ & Gonadectomy age (yr) \\
\hline $45, X / 46, X, r(?)$ & 30 & 12 & 13 \\
$45, X$ & 30 & 6 & 10 \\
$45, X$ & 30 & 17 & 23 \\
$45, X$ & 45 & 15 & 17 \\
$45, X / 47, X+$ mar1,+mar2, $/ 48, X+$ mar1,+mar2,+mar3 & $53(32 / 12 / 9)$ & 13 & 15 \\
$45, X / 46, X, r(?)$ & $30(6 / 24)$ & 10 & 15 \\
$45, X / 46, X, r(?)$ & $15(6 / 9)$ & 10 & 20 \\
$45, X$ & 20 & 1 & Did not perform \\
$45, X$ & 30 & 13 & Did not perform \\
$45, X$ & 30 & 13 & Did not perform \\
$45, X$ & 30 & 4 & Did not perform \\
$45, X$ & 30 & 1 & Did not perform \\
$45, X$ & 40 & Did not perform \\
$45, X$ & 30 & Did not perform \\
\hline
\end{tabular}

a classic pattern containing fibrous connective bundles with ovarian-like stroma and no germ cells, with or without isolated inclusion cysts lined by cuboidal epithelium. Such a pattern presented no evidence of malignancy. However, the risk of developing such tumors is uncertain, as not all patients with a $\mathrm{Y}$ chromosome revealed by techniques other than conventional karyotyping have undergone gonadectomy. In addition, gonadectomy has been performed prophylactically, with the aim of preventing onset of gonadoblastoma or dysgerminoma. Pelvic ultrasound identified a small uterus and lack of ovaries in $80 \%$ of patients and normal kidney and urinary tract in all patients. Only 2 patients presented aortic coarctation on echocardiography. There was great variability in height as some patients had received growth hormone.

To characterize the distribution of relative frequency for qualitative covariates using the equality test of 2 proportions,
Table 3. Frequency distribution of covariates: karyotype and molecular examination

\begin{tabular}{lcc}
\hline Covariates & No. (\%) & $P$-value \\
\hline Karyotype & & $<0.001$ \\
$45, X$ & $101(92.7)$ & \\
Mosaic & $8(7.3)$ & $<0.001$ \\
Blood/oral swab & & \\
Negative & $95(87.2)$ & \\
Positive & $14(12.8)$ & \\
\hline
\end{tabular}

there was statistical significance in the distribution of the karyotype $45, X(92.7 \%)$ and $7.3 \%$ mosaicism $(P<0.001)$, as well as in the distribution of the molecular results, where we observed $87.2 \%$ negative results and $12.8 \%$ positive $(P<0.001)$ (Table 3).

Fleiss' kappa analysis showed a degree of agreement of 1 
Table 4. Comparative analysis between the 2 tissues (blood and oral mucosa)

\begin{tabular}{|c|c|c|c|c|c|c|}
\hline \multirow{2}{*}{ Tissues } & \multicolumn{3}{|c|}{ Blood } & \multicolumn{3}{|c|}{ Statistics } \\
\hline & Negative & Positive & Total & $P$-value & Sensitivity & Specificity \\
\hline Oral swab TSPY & & & & $<0.001$ & $100 \%$ & $100 \%$ \\
\hline Negative & 95 & 0 & 95 & & & \\
\hline Positive & 0 & 14 & 14 & & & \\
\hline Oral swab SRY & & & & $<0.001$ & $100 \%$ & $100 \%$ \\
\hline Negative & 95 & 0 & 95 & & & \\
\hline Positive & 0 & 14 & 14 & & & \\
\hline
\end{tabular}

$(P<0.001)$ between the 2 tissues for the 2 molecular markers. When measuring the relationship between the results in the 2 tissues for the molecular markers, as well as the sensitivity and specificity, using the chi-square test, we concluded that, for both TSPY and SRY, the relationship between the results in the 2 tissues was statistically significant, showing maximum indexes of sensitivity and specificity of 100\% (Table 4).

\section{Discussion}

This study investigated the presence of occult mosaicism of the Y chromosome in 109 patients with TS and compared 2 tissues of different embryonic origins. Fragments of the $\mathrm{Y}$ chromosome were detected by mPCR in both tissues of $12.8 \%$ of the patients, with $92.7 \%$ presenting with X-chromosome monosomy in the classic cytogenetic analysis. We did not observe any specific phenotypic expression that could differentiate between patients with and without markers for Y-chromosome fragments.

Karyotyping used the G-band technique in peripheral blood as a routine examination for diagnosis of TS. An important aspect to be considered in relation to the sensitivity of the karyotype in this study is the number of metaphases analyzed in the classic karyotype. According to the latest consensus for TS and in accordance with the recommendation of the American College of Medical Genetics, all women with suspected TS should undergo karyotyping with analysis of at least 20 cells. However, this method has identified only 14\% (95\% CI) of blood mosaicisms. If mosaicism is suspected, whether or not it is demonstrated in the karyotype, it is recommended that additional metaphases be analyzed or that more sensitive studies such as in situ hybridization (FISH) and PCR ${ }^{19)}$ be performed. In the authors' experience, karyotyping of 142 patients diagnosed with TS showed $71 \%$ with karyotype 45 , X among an average of 30 metaphases (ranging from 15 to 53), a percentage higher than that described in other studies, in which monosomy of $\mathrm{X}$ affected 40 to $50 \%$ of patients with $\mathrm{TS}^{20-23)}$

Although karyotyping of peripheral blood is generally suitable, a second tissue, such as skin fibroblasts, oral mucosa cells, or urine sampled for bladder epithelial cells, can be examined if there is a strong clinical suspicion of TS when the karyotype is normal or shows low mosaicism. ${ }^{19)}$ In a study carried out with the FISH technique in 12 patients with TS, peripheral blood leukocytes and oral mucosa swabs and, later, ovarian tissue, showed the same proportion of positivity. These results indicate that $\mathrm{Y}$ chromosomal material in these tissues can be used as a predictor of the presence of a Y fragment in the gonads, which is important for identification of women at risk of gonadoblastoma. ${ }^{24)}$

Detection of Y chromosome mosaicism is clinically important due to the risk of tumor development, especially gonadoblastoma, in patients with dysgenetic gonads, those presenting a karyotype with X monosomy, and/or those with a marker chromosome or ring chromosome, as in TS. ${ }^{25,26)}$ Gonadoblastoma is a mixed tumor of benign undifferentiated cells that becomes a dysgerminoma or other forms of malignant germ cell tumors in $60 \%$ of cases. ${ }^{27)}$

In this study, molecular analysis was carried out in 2 tissues of different embryonic origins using the same markers and molecular technique (mPCR), unlike most published works, to assess the best tissue for detecting mosaicism. ${ }^{14,25,27-30)}$ We found the same positivity in relation to the 2 tissues, peripheral blood leukocytes and oral mucosa swabs, with a degree of agreement of 1 and sensitivity and specificity of $100 \%$. These data are similar to those of previous studies; however, those studies used FISH as a molecular technique ${ }^{21,30)}$ or FISH and conventional PCR. ${ }^{31)}$

Thus, the karyotype, despite being considered the gold standard for laboratory diagnosis of TS, has a low sensitivity (17.6\%) for identifying Y chromosome mosaicism compared to $\mathrm{mPCR}$. Another important result was the greater positivity in the molecular study (71.4\%) in patients with X monosomy, which shows the need to expand the number of karyotype metaphases analyzed and the performance of additional tests to detect hidden mosaicism. ${ }^{5,19)}$

In conclusion, although classic cytogenetics is considered the best methodology for diagnosis of TS, detection of mosaicism at a degree less than $10 \%$ can be lost, requiring the use of more sensitive methods, such as the easy to perform mPCR procedure (fast, low cost, and sensitive), to detect the presence of $\mathrm{Y}$ chromosome derivatives. This should be coupled with analysis of tissues with different embryonic origins such as blood and oral tissue, since tissue mosaicism is variable, to predict the future risk of gonadoblastoma. The advantages of using oral mucosa cells over peripheral blood lymphocytes are a simpler and less invasive method of collection, less time required for DNA extraction, and lower cost. 


\section{Ethical statement}

The study was approved by the Medical Ethics and Research Committee (CAE: 48099115.0.0000.5505), and all participants signed an informed consent form.

\section{Conflict of interest}

No potential conflict of interest relevant to this article was reported.

\section{Funding}

This research received no specific grant from any funding agency in the public, commercial, or not-for-profit sectors.

\section{References}

1. Turner HH. A Syndrome of infantilism, congenital webbed neck, and cubitus valgus. Endocrinology 1938;23:566-74.

2. Daggag H, Srour W, El-Khateeb M, Ajlouni K. Analysis of Turner syndrome patients within the Jordanian population, with a focus on four patients with Y chromosome abnormalities. Sex Dev 2013;7:295-302.

3. Canto P, Kofman-Alfaro S, Jiménez AL, Söderlund D, Barrón C, Reyes E, et al. Gonadoblastoma in Turner syndrome patients with nonmosaic 45, X karyotype and Y chromosome sequences. Cancer Genet Cytogenet 2004;150:70-2.

4. Sallai A, Sólyom J, Dobos M, Szabó J, Halász Z, Ságodi L, et al. Y-chromosome markers in Turner syndrome: Screening of 130 patients. J Endocrinol Invest 2010;33:222-7.

5. Hook EB. Exclusion of chromosomal mosaicism: tables of 90\%, 95\% and 99\% confidence limits and comments on use. Am J Hum Genet 1977;29:94-7.

6. Larsen T, Gravholt CH, Tillebeck A, Larsen H, Jensen $\mathrm{MB}$, Nielsen J, et al. Parental origin of the X chromosome, $\mathrm{X}$ chromosome mosaicism and screening for "hidden" Y chromosome in 45, X Turner syndrome ascertained cytogenetically. Clin Genet 1995;48:6-11.

7. Medlej R, Lobaccaro JM, Berta P, Belon C, Leheup B, Toublanc JE, et al. Screening for Y-derived sex determining gene SRY in 40 patients with Turner syndrome. J Clin Endocrinol Metab 1992;75:1289-92.

8. Vollrath D, Foote S, Hilton A, Brown LG, Beer-Romero P, Bogan JS, et al. The human Y chromosome: a 43-interval map based on naturally occurring deletions. Science 1992;258:52-9.

9. Chu CE, Connor JM, Donaldson MD, Kelnar CJ, Smail PJ, Greene SA. Detection of Y mosaicism in patients with Turner's syndrome. J Med Genet 1995;32:578-80.

10. Henegariu O, Heerema NA, Dlouhy SR, Vance GH, Vogt PH. Multiplex PCR: critical parameters and step-by-step protocol. Biotechniques 1997;23:504-11.

11. Elnifro EM, Ashshi AM, Cooper RJ, Klapper PE. Multiplex PCR: optimization and application in diagnostic virology. Clin Microbiol Rev 2000;13:559-70.

12. Butler E, Li R. Genetic Markers for Sex Identification in Forensic DNA Analysis. J Forensic Investig 2014;2:1-10.

13. Barbosa LG, Souza MA, Siviero-Miachon AA, Dias-daSilva, MR, Spinola-Castro AM. Y Chromosome sequences in Turner syndrome: multiplex PCR, a new method for diagnosis. J Genet Genome Res 2020;7:052.

14. Kizys MM, Cardoso MG, Lindsey SC, Harada MY, Soares FA, Melo MC, et al. Optimizing nucleic acid extraction from thyroid fine-needle aspiration cells in stained slides, formalin-fixed/paraffin-embedded tissues, and longterm stored blood samples. Arq Bras Endocrinol Metabol 2012;56:618-26.

15. Mendes JR, Strufaldi MW, Delcelo R, Moisés RC, Vieira JG, Kasamatsu TS, et al. Y-chromosome identification by PCR and gonadal histopathology in Turner's syndrome without overt Y-mosaicism. Clin Endocrinol (Oxf) 1999;50:19-26.

16. Araujo C, Galera MF, Galera BB, Silvestre FG, Medeiros SF. Molecular identification of chromosome $\mathrm{Y}$ sequences in Brazilian patients with Turner syndrome. Gynecol Endocrinol 2008;24:713-7.

17. Bianco B, Lipay M, Guedes A, Oliveira K, Verreschi IT. SRY gene increases the risk of developing gonadoblastoma and/ or nontumoral gonadal lesions in Turner syndrome. Int J Gynecol Pathol 2009;28:197-202.

18. Rojek A, Obara-Moszynska M, Kolesinska Z, RabskaPietrzak B, Niedziela M. Molecular Detection and Incidence of Y Chromosomal Material in Patients with Turner Syndrome. Sex Dev 2017;11:254-61.

19. Gravholt CH, Andersen NH, Conway GS, Dekkers OM, Geffner ME, Klein KO, et al. Clinical practice guidelines for the care of girls and women with Turner syndrome: proceedings from the 2016 Cincinnati International Turner Syndrome Meeting. Eur J Endocrinol 2017;177:G1-70.

20. Miclea DL, Grigorescu-Sido P, Bucerzan S, Pop IV. Y chromosome in Turner syndrome and FISH technique usefulness in cytogenetic diagnosis. Rev Romana de Medicina de Lab 2012;20:327-33.

21. Hanson L, Bryman I, Janson PO, Jakobsen AM, Hanson C. Fluorescence in situ hybridisation analysis and ovarian histology of women with Turner syndrome presenting with Y-chromosomal material: a correlation between oral epithelial cells, lymphocytes and ovarian tissue. Hereditas 2002;137:1-6.

22. Knauer-Fischer S, Besikoglu B, Inta I, Kneppo C, Vogt PH, Bettendorf M. Analyses of Gonadoblastoma Y (GBY)-locus and of Y centromere in Turner syndrome patients. Exp Clin Endocrinol Diabetes 2015;123:61-5.

23. Scully RE. Gonadoblastoma. A review of 74 cases. Cancer 1970;25:1340-56.

24. Bianco B, Nunes Lipay MV, Guedes AD, Verreschi IT. Clinical implications of the detection of Y-chromosome 
mosaicism in Turner's syndrome: report of 3 cases. Fertil Steril 2008;90:1197.e17-20.

25. Saenger P. Clinical review 48: The current status of diagnosis and therapeutic intervention in Turner's syndrome. J Clin Endocrinol Metab 1993;77:297-301.

26. Quilter CR, Taylor K, Conway GS, Nathwani N, Delhanty JD. Cytogenetic and molecular investigations of $Y$ chromosome sequences and their role in Turner syndrome. Ann Hum Genet 1998;62(Pt 2):99-106.

27. Robinson DO, Dalton P, Jacobs PA, Mosse K, Power MM, Skuse DH, et al. A molecular and FISH analysis of structurally abnormal Y chromosomes in patients with Turner syndrome. J Med Genet 1999;36:279-84.

28. Nazarenko SA, Timoshevsky VA, Sukhanova NN. High frequency of tissue-specific mosaicism in Turner syndrome patients. Clin Genet 1999;56:59-65.
29. Canto P, de la Chesnaye E, López M, Cervantes A, Chávez $\mathrm{B}$, Vilchis F, et al. A mutation in the $5^{\prime}$ non-high mobility group box region of the SRY gene in patients with Turner syndrome and Y mosaicism. J Clin Endocrinol Metab 2000;85:1908-11.

30. Freriks K, Timmers HJ, Netea-Maier RT, Beerendonk CC, Otten BJ, van Alfen-van der Velden JA, et al. Buccal cell FISH and blood PCR-Y detect high rates of X chromosomal mosaicism and $Y$ chromosomal derivatives in patients with Turner syndrome. Eur J Med Genet 2013;56:497-501.

31. Ferrão L, Lopes ML, Limbert C, Marques B, Boieiro F, Silva $\mathrm{M}$, et al. Pesquisa de sequências do cromossoma $\mathrm{Y}$ em indivíduos com síndroma de Turner [Screening for Y chromosome sequences in patients with Turner syndrome]. Acta Med Port 2002;15:89-100. 